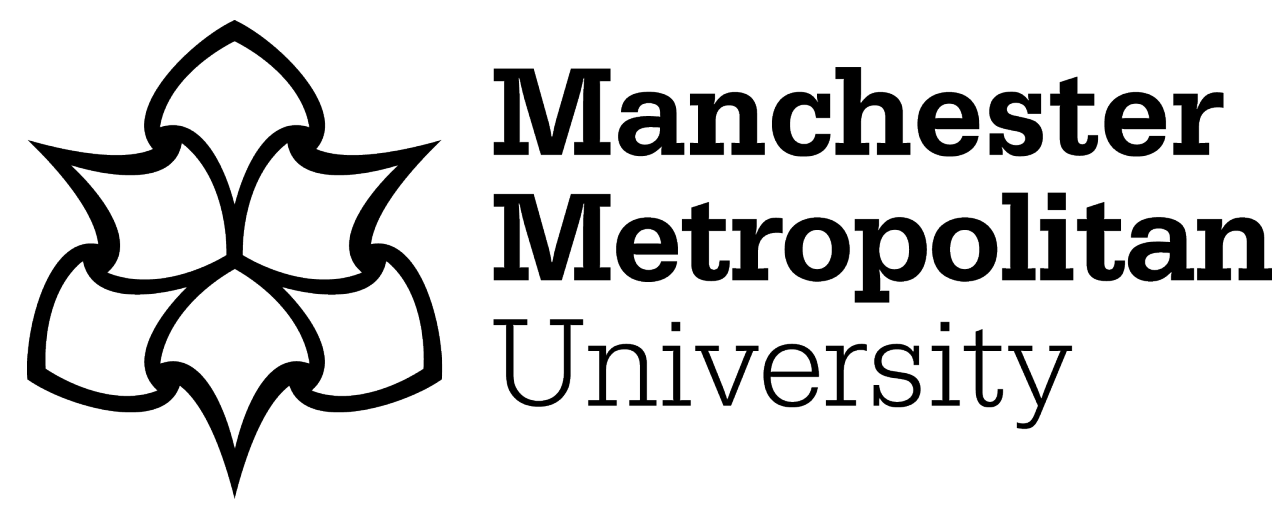

Kitching, J and Rouse, J (2017) Opportunity or dead end? Rethinking the study of entrepreneurial action without a concept of opportunity. International Small Business Journal, 35 (5). pp. 558-577. ISSN 0266-2426

Downloaded from: https://e-space.mmu.ac.uk/617992/

Version: Accepted Version

Publisher: Sage Publications

DOI: https://doi.org/10.1177/0266242616652211

Please cite the published version 


\title{
Opportunity or dead end? \\ Rethinking the study of entrepreneurial action without a concept of opportunity
}

John Kitching

Small Business Research Centre, Kingston University, UK.

Email: j.kitching@kingston.ac.uk

Julia Rouse

Sylvia Pankhurst Gender Research Centre, Manchester Metropolitan University, UK.

Email: J.Rouse@mmu.ac.uk

\begin{abstract}
:
This paper has two objectives: to critique the dominant opportunity discovery and creation literatures, and; to propose a new, critical realist-inspired analytical framework to theorise the causes, processes and consequences of entrepreneurial action - one that needs no concept of opportunity. We offer three reasons to support our critique of opportunity studies. First, there are important absences, contradictions and inconsistencies in definitions of opportunity in theoretical and empirical work that mean the term cannot signal a clear direction for theorising or empirical research. Our central criticism is that the concept of opportunity cannot refer simultaneously, without contradiction, to a social context offering profit-making prospects, to particular practices, and to agents' subjective beliefs or imagined futures. Second, a new definition of opportunity would perpetuate the conceptual chaos. Third, useful concepts to capture important entrepreneurial processes are readily available, for instance, combining resources, creating new ventures and achieving product sales, which render a concept of opportunity superfluous. Instead, we conceptualise entrepreneurial action as investments in resources intended to create new goods and services for market exchange emergent from the interaction between agential, socialstructural and cultural causal powers.
\end{abstract}

Keywords: opportunity, discovery, creation, critical realism, entrepreneurial action 


\section{INTRODUCTION}

"Our field is fundamentally concerned with understanding how, in the absence of current markets for future goods and services, these goods and services manage to come into existence. Thus entrepreneurship as a scholarly field seeks to understand how opportunities to bring into existence 'future' goods and services are discovered, created, and exploited, by whom, and with what consequences." (Venkataraman 1997:120, italics in original)

Since these words were written, opportunity has perhaps become the central organising concept in the study of entrepreneurship (Busenitz et al. 2014). What is striking re-reading Venkataraman, widely cited as a landmark publication redirecting research attention towards opportunities, is how influential the second sentence has been, yet the first sentence defines the entrepreneurship field without a concept of opportunity. We agree with Davidsson (2015) that the phenomena discussed under the label of 'entrepreneurial opportunities' are important but we are sceptical that the concept of opportunity helps to explain adequately the causes, processes and consequences of entrepreneurial action. This paper therefore has two objectives: first, to challenge the consensus (Zahra and Wright 2011) surrounding the value of the concept of opportunity evident in the entrepreneurship literature by critiquing the dominant discovery and creation approaches; and, second, to outline a critical realist-informed approach to the study of entrepreneurial action that needs no concept of opportunity.

Powerful theory in entrepreneurship, as in the social sciences more generally (Sayer 1992), requires precisely defined concepts (Bygrave and Hofer 1991). The fundamental question is 
whether social scientists define and deploy the concept of opportunity in cogent and consistent ways that enable robust explanations of important entrepreneurial processes. We therefore depart from the view of Crawford et al. (2016) that 'what is an opportunity?' is the wrong question. For those who believe opportunity is an important concept, it is vital it is defined coherently if it is to contribute to knowledge.

Our principal concern is not to advance a new theory of opportunity but to question whether we should conceptualise entrepreneurial action within an opportunity framework at all. We offer three sets of reasons to support our argument: one, the absences, contradictions and inconsistencies in definitions of opportunity in theoretical and empirical work; two, the risk that proposing a new definition of opportunity would perpetuate the conceptual chaos; and, three, the ready availability of useful concepts to capture important entrepreneurial processes such as imagining a business idea, acquiring, combining and mobilising resources, networking with stakeholders, creating a new venture and achieving a product sale - all of which render a concept of opportunity superfluous. We propose to replace opportunity with a new analytical framework, one intended to theorise entrepreneurial action, defined as investments in resources intended to produce goods and services for market exchange, in terms of the interaction of agential, social-structural and cultural causal powers. These resource investments we describe as entrepreneurial projects.

The popularity of the opportunity concept means it has become a convenient hook upon which to hang an analysis but because its referents are highly elastic, its contribution to understanding entrepreneurial processes is profoundly ambiguous. Users of the concept 
often switch, without acknowledgment, between radically different meanings of opportunity in their theoretical and empirical work: as social situations possessing profitmaking potential; as specific activities, including making sales; and as agential beliefs or imagined futures. This easy elision of different definitions constitutes a major impediment to explanation of entrepreneurial processes. As studies take different referents for the concept of opportunity, or none at all, the term does not signal a clear direction for theorising or empirical research (Görling and Rehn 2008; Hansen et al. 2011; Arend 2014). Davidsson (2015) found that 80 per cent of 210 studies reviewed provided no definition, while others offered multiple definitions within a single work. We accept that conceptual ambiguity might stimulate advances in an emerging field by encouraging multiple lines of theorising and research but, over time, a lack of conceptual clarity becomes a major obstacle to theory development. The opportunity concept has arguably become an empty signifier, a catch-all construct used to refer to any aspect of entrepreneurial thought, action or environment deemed interesting. Opportunity studies simply do not cumulate to provide, or support, a progressively developing theorisation of entrepreneurial action.

This conceptual confusion is an emergent property of the field. It is not the fault of any single author, or group of authors, although we do believe that advocates of opportunity creation, whom we discuss later, might have served the field better by introducing a new/different conceptual vocabulary to specify their particular objects of interest rather than referring to them as opportunities.

Several alternative ways of dealing with the morass of opportunity definitions are possible. First, we could live with multiple meanings and request that researchers make clear their 
position before presenting findings. Davidsson (2015) suggests most do not do this; rather, many cite previous work as authority for their own approach. But even if researchers set out their definitions as requested, this only institutionalises the current conceptual quagmire. Second, we might retain one definition of opportunity and drop the others. Unfortunately, the available definitions, taken singly, are used in inconsistent ways; collectively, they have produced a muddle. Nor, we feel, can the problem be remedied by redefinition. Indeed, our initial aim was to propose a new definition, intended to synthesise and supersede earlier ones, but, for reasons we hope to make clear, we decided this would not be possible.

Third, we might take a different path, one that avoids the term opportunity. It is because the term opportunity has become invested with conflicting meanings and, less visibly, incorporated contradictory ontological commitments that we decided to write this paper. We conclude that the concept of opportunity should be dropped from the entrepreneurship lexicon - a view shared or implied by others (Gartner 2003; Davidsson 2015). We recognise others might not wish to discard the term altogether, even if persuaded of our arguments, because our proposition is radical. Our work should therefore be seen as a contribution to the conversation about the value of the opportunity concept and as an argument for a different approach.

Drawing on critical realist philosophy of science (Bhaskar 1978, 1979; Collier 1994; Sayer 2000), our second, more positive, aim is to propose a new non-opportunity-based framework for studying entrepreneurial action. We conceptualise entrepreneurial action as a socio-historical process of creating new goods and services for market exchange emergent from the interaction between entrepreneurs and their structural and cultural contexts. The 
term 'new' connotes no profound novelty; it encompasses goods and services imitating those already in existence. We disagree with those who claim critical realism necessarily entails a commitment to the discovery approach (Alvarez and Barney 2010) while agreeing with others that action - not opportunity - should be the focus of attention (Foss and Klein 2012; Spedale and Watson 2014), although we stress that all action needs to be explained in relation to a wider structural and cultural context. There are no context-free actions (Archer 1995). In line with calls to pay greater attention to context (Zahra et al. 2014), our approach aims to facilitate more fruitful theorising, particularly of the multi-stranded influence of context on entrepreneurial action, than a framework founded on the slippery notion of opportunity.

We believe that failure to engage in ontological theorising has been an unrecognised source of problems in using the concept of opportunity, enabling researchers to move between a melange of meanings without fully considering the implications for their analyses. Recent attempts to revitalise the concept of opportunity, drawing on similar critical realist ideas to those elaborated here (Martin and Wilson 2014; Ramoglou and Tsang 2015; Wilson and Martin 2015), generate genuine insights - but by adding another layer of meaning to the term, paradoxically, threaten to amplify the confusion we seek to combat. No argument can conclusively settle the debate about the value of the opportunity concept but it is legitimate to ask whether the entrepreneurship field is progressing or degenerating with contradictory conceptions of opportunity in play. We do, however, welcome these efforts to engage explicitly with ontology and, more specifically, for developing critical realist-inspired analyses. This paper seeks to complement these works while decoupling critical realist analysis from the concept of opportunity. 
The next section sets out the key features of critical realist social ontology and argues its relevance for theorising entrepreneurial action. We then critique the dominant discovery and creation conceptions of opportunity, and attempts to synthesise the two, from a critical realist standpoint. Finally, we set out an alternative approach for the study of entrepreneurial action and illustrate the possibilities with examples from the literature that come closest to the type of approach we propose.

\section{USING CRITICAL REALISM TO STUDY ENTREPRENEURIAL ACTION}

Social science research is necessarily informed by metatheoretical assumptions regarding the nature of the human-made world (ontology) (Bhaskar 1979). Contrary to Dimov (2007), one cannot be silent on ontology. Ontological commitments are non-optional (Fleetwood 2005); failure to be explicit about them only leads to their unacknowledged reintroduction into analysis and explanation. Such assumptions necessarily influence research practice, shaping conceptions of the social objects ${ }^{1}$ studied and the methods used to study them. Critical realism sets out particular ontological commitments (Bhaskar 1979; Lawson 1997; Sayer 2000; Groff 2004; Elder-Vass 2010), licensing a range of theories that are consistent with them, while ruling out those that are inconsistent as either false or incomplete (Bhaskar 1978). There is no single critical realist theory of entrepreneurial action - or of anything else. Critical realism

\footnotetext{
${ }^{1}$ The concept 'social object' refers to any human-made, socially real entity (Fleetwood 2005 ) that is the product of human interaction that researchers conceptualise and study in their theoretical and empirical work. Examples include organisations, markets and cultures. This definition excludes materially real artefacts such as cars, computers and chairs. Social objects may, but need not, reflect purposeful design. The concept does not imply social objects exist fully autonomously from the people whose activities produce them, that such objects possess invariant properties through time or that these objects determine how agents act.
} 
cannot adjudicate between rival theories that are consistent with its ontological assumptions; these are substantive matters for researchers in the respective fields to debate.

Here we outline three important critical realist ideas to critique the dominant conceptions of opportunity. From the early work of Bhaskar $(1978,1979)$, we draw two key concepts: ontological intransitivity and the stratification of social reality. From Archer (1995) we introduce analytical dualism, a method that can provide powerful conceptual tools to theorise the causes, processes and consequences of entrepreneurial action.

First, realist social science presupposes that social objects are intransitive: that is, they exist and act independently of the researcher's identification, or conceptual, linguistic or discursive constructions, of them (Bhaskar 1978; Collier 1994). Without a commitment to realism, knowledge claims cannot be made at all because there are no independently existing and acting objects to know (Searle 2010). The real is whatever exists, whether mountains, rivers or human beings, their activities, institutions and experiences, including the generative causal powers that produce these entities (Sayer 2000). Social objects, like natural ones, are objective in that they exist independently of whether the researcher observes them or not (Bhaskar 1979; Fleetwood 2005). It is a common misconception that realism and constructionism are necessarily opposed. Critical realists can accept fully that the social world is made by people's activities, they just hold back from claiming that the reality of social processes is exhausted by agents' culturally-shaped descriptions (or constructions) of them (Elder-Vass 2012; Ramoglou and Tsang 2015). Even radical Austrian subjectivists who emphasise the crucial role of imagined futures as influences on 
entrepreneurial action (Chiles et al. 2010), presuppose the existence of a specific class of agents (entrepreneurs) with particular powers (the capacity to exercise imagination and choice), as well as particular non-agential, social objects (markets) that arise from entrepreneurial activities. To conceptualise opportunities, and to claim to study them, therefore, is to presuppose their independent existence.

Social objects are concept-dependent, that is, their existence necessarily depends on human agents possessing some conception of what they are doing when they act in ways that contribute to the production of such objects, whether intentionally or inadvertently (Bhaskar 1979; Sayer 1992). For instance, new ventures exist because the agents involved (entrepreneur, investors, employees, customers) act - not just talk - in particular ways. But, this does not mean discursive constructions of activities and their effects are exhaustive of social reality (Fleetwood 2005). Agents involved in the production of social objects do not possess full awareness of the consequences of their actions. Entrepreneurs forming new ventures contribute to the transformation of a market economy whether or not they intend or understand this. Venture creation is likely to generate responses from stakeholders which might or might not be perceived by the entrepreneur. Social objects such as organisations and markets are capable of generating effects independently of the way both the agents studied and the researchers studying them construct them in thought or discourse (Groff 2008).

Second, critical realists argue that the social world is stratified, comprising distinct, though related, domains (Bhaskar 1978, 1979): the empirical (experiences, beliefs, imagined 
futures); the actual (actions, events); and the real or deep ${ }^{2}$ (the generative causal powers that produce actions or events). ${ }^{3}$ The real/deep level encompasses actual and empirical levels, and the actual incorporates the empirical. The social world is an open, structured, unfolding process, in which actions and events are caused by multiple, interacting powers (Bhaskar 1979). Because of this openness, the operation of powers (at the deep level) contributes to the production of a wide range of actions and events (at the actual level) that may or may not be observed (at the empirical level). The activation of particular causal powers does not necessarily lead to event regularities or to events that are observed. Theorising causal powers and their effects in terms of observable manifestations is to reduce the 'deep' ontology of critical realism to a 'flat' ontology of experience. So, how do proponents of the opportunity concept conceptualise opportunities - as agential beliefs, as actions or events, or as generative causal powers? It is vital that researchers propose coherent conceptions of opportunity and apply them consistently.

Third, Archer's (1995) analytical dualism provides a framework connecting the deep social ontology of critical realism with theory seeking to explain how social objects are produced, intentionally or inadvertently, by particular agents in particular contexts (Bhaskar 1979). The existence and activity of social objects are both agent- and context-dependent; explanations of entrepreneurial action therefore require reference to both. The social context might be

\footnotetext{
${ }^{2}$ Fleetwood (2005), following Lawson (1995), prefers the term 'deep' to Bhaskar's (1978) designation of the 'real' level to avoid confusion; all three levels are real.

${ }^{3}$ Scientists identify the causal powers of objects in laboratory experiments by eliminating the effects of others (Bhaskar 1978). Outside the laboratory, objects continue to act according to their powers, though their effects vary because the world is an open system, with multiple interacting powers contributing to the production of events. This ontological distinction between causal powers and events is fundamental to critical realism.
} 
separated into structure and culture. ${ }^{4}$ Entrepreneurs are variably positioned in relation to relatively enduring social structures and cultures (Bhaskar 1979; Archer 1988). Structures such as organisations and markets are constituted by relationships between internallyrelated positions, ${ }^{5}$ possessing the power to influence the exercise of agency by those occupying particular positions. For example, markets are structures that affect the activities of the buyers and sellers whose relations constitute them, rendering particular actions possible or impossible, easy or difficult, rewarding or costly. This structural conception of context can be contrasted with individualist, voluntarist accounts that treat agential interaction as purely contingent, implicitly assuming that individuals might meet and form relationships with any other (Archer 2014). A structural conception of relationships facilitates robust explanations of entrepreneurial action that avoid the twin problems of determinism (where events are explained solely in terms of the operation of structural forces, ignoring agent choice) and of voluntarism (where events are explained solely in terms of agent motivations without acknowledgement of the structural and cultural conditions that make them possible).

Structures and cultures impact agents by shaping the situations they confront, which facilitate or frustrate the conception and attainment of particular projects (Archer 1995). Layder (2006) distinguishes three types of context in terms of agents' capacities to

\footnotetext{
${ }^{4}$ Structure and culture are separated to make clear that both social roles and relationships and ideas, meanings, norms and discourses are non-agential, socially real, causally efficacious entities possessing powers to influence the exercise of agency (Elder-Vass 2012). Agents may be able to give discursive accounts of their motivations but may be less conscious of the embeddedness of those motives in a deeper cultural context (Porpora 2015).

${ }^{5}$ Positions are internally related when their existence and causal powers necessarily depend on relations with others. Examples include employer and employee, and buyer and seller.
} 
transform them - these are situated activity, the arena of personal interaction; social settings, the reproduced social relations, positions and practices that constitute the broader context of situated activity; and the distribution of material and cultural resources across major social groups (such as class, gender and ethnicity) that influence the reproduction of social relations, positions and practices. The arena of personal interaction is more amenable to transformation by individual agents than are social settings which, in turn, are more pliable than the domain of material and cultural resources.

Archer $(1995,2014)$ elaborates the process of interaction between structure, culture and agency through time in the form of a 3-part morphogenetic cycle of structural and cultural conditioning, social interaction, and structural and cultural elaboration. This is an analytical model; in practice, conditioning, interaction and elaboration occur continuously in relation to the multiple structures and cultures within which agents act. Several points about structure and culture require emphasis. First, structures and cultures are necessary conditions for any intentional social act. The exercise of agency presupposes some context, for example, purchasing raw materials presupposes the existence of factor markets. Agents necessarily seek to realise their projects in structural and cultural circumstances largely not of their own making. Second, structures and cultures possess causal powers irreducible to those of the agents whose relations constitute them. Markets, for instance, might be distinguished in terms of the nature and level of competition. These structural properties of markets exist only because of agents' activities, and influence what agents are able to do but are not themselves properties of agents. 
Third, structures and cultures only generate effects through the exercise of agency, by conditioning (enabling, motivating and constraining) - but not determining - the activities of particular agents pursuing particular projects. Structural and cultural positioning enables particular agents to act in particular ways, both reflexively and habitually or unselfconsciously (Fleetwood 2008; Sayer 2009; Akram 2013), whether or not agents are aware of such enablements. Agents are able, to variable degrees, to reflect on their circumstances, dedicate themselves to particular projects which they subjectively value (such as starting a new venture), and choose to act in ways they believe, fallibly, will realise those projects (Archer 2000, 2003). Agents always possess a degree of discretion to act otherwise, even if this might incur high personal costs, because behaviour is shaped partly by the contradictory pressures imparted by particular structures (Luke and Bates 2015) and cultures, and partly by agents' simultaneous positioning within multiple structures and cultures, each offering a different profile of enablements, incentives and constraints (Martinez Dy et al. 2014).

Fourth, conditioned agential interaction, in turn, generates structural and cultural elaboration. Structures and cultures are reproduced or transformed over time by agents' activities, intentionally and inadvertently. Transformation gives rise to emergent structural and cultural causal powers that influence the exercise of future agency. Markets, for instance, may become more, or less, competitive over time as a consequence of buyer/seller interaction, with consequences for the future action of all. The dynamic openness of society permits novel forms of conditioned activity; agents can act creatively but not just as they please. 
We emphasise the purpose of critical realist-informed analysis is explanation - not prediction (Bhaskar 1978). Explanation requires the development of concepts that abstract from the particularities of actual, concrete cases to capture the necessary properties and powers that make social objects what they are, and to distinguish these from purely contingent features (Sayer 1992). Formal organisations, as a particular kind of entity, for instance, can be conceptualised abstractly as social entities with designated roles defined in terms of specific rights and obligations, and relations between these roles, despite contingent differences such as the particular people who currently occupy these roles. The study of any actual, concrete organisation must take into account the multiplicity of necessary and contingent influences on organisational practices and their consequences, including agents' beliefs about, and intentions towards, their roles and relationships. But these agential properties and powers should not form part of the abstract definition of formal organisation.

The openness of the social world and the emergence of novel structural, cultural and agential powers over time mean that there is an important asymmetry between explanation and prediction (Sayer 1992). Although retrospectively we can often give well-grounded explanations of past events, prospectively we are very rarely, if ever, able to do so because we do not know which of the myriad of possible sets of circumstances, intrinsic as well as extrinsic to the agent, will actually materialise (Bhaskar 1986).

We now turn to examine the major approaches to the conception and study of opportunity discovery and creation - using the lens of a critical realist commitment to an intransitive, structured, open, transformable and emergent social world. We seek to show how the 
major approaches either do not deal explicitly with the issue of social ontology, while implicitly drawing on similar ideas to critical realism (discovery), or make unwarranted links between ontology and the particular positions adopted or rejected (creation). Both cause serious problems for users of the opportunity concept.

\section{OPPORTUNITY DISCOVERY}

Advocates of the discovery approach conceptualise opportunities as social situations with particular properties existing independently of any observer. Kirzner (1973) is often considered the progenitor of this approach with his description of opportunities as hitherto unnoticed possibilities for profit. In later work, Kirzner (2009) clarified that discovery is a metaphor intended to describe the function entrepreneurs perform in moving an economy from disequilibrium to equilibrium, rather than a description of what entrepreneurs subjectively perceive themselves to be doing. Klein (2008) suggests those who followed Kirzner misused his work by transposing his macro-level metaphor of opportunity into a micro-level concept referring to the context within which individual entrepreneurs act.

The discovery approach is best exemplified by Shane's (2003) individual-opportunity nexus, which links enterprising individuals to independently existing lucrative opportunities (see also Shane 2000, 2012; Shane and Venkataraman 2000; Eckhardt and Shane 2003, 2010). In what follows we distinguish a primary and an unintended secondary view for Shane. In the primary view, the one most cited in the literature, independently existing opportunities are argued to arise from technological, political/regulatory and social/demographic changes that create market imperfections. Opportunity discovery and exploitation are conceived as distinct moments in an historical process: discovery necessarily pre-dates exploitation. The 
'favorability' of an opportunity as a desired, successful outcome for the entrepreneur is presupposed in discovery accounts (Davidsson 2015). As effects are only discoverable subsequent to action, the term opportunity can only be justified retrospectively (Gartner et al. 2003; Dimov 2011). Using the term opportunity prospectively in discovery accounts is illegitimate because the (successful) effects of action cannot be known at that time. ${ }^{6}$

On closer examination, however, we find that Shane (2003) also works with a secondary view, a different conception of opportunity: as a situation in which entrepreneurs believe profit-making prospects exist. This approach is confirmed by his acceptance that opportunities need not be successful (Shane 2003:9). The switch to opportunity as belief may appear innocuous but this makes the existence of an opportunity observer-dependent and observer-relative because it acknowledges perceptions of profit-making possibilities are fallible. Shane's observer-dependent definitions of opportunity are presented below.

\footnotetext{
"I define an entrepreneurial opportunity as a situation in which a person can create a new means-ends framework for recombining resources that the entrepreneur believes will yield a profit" (Shane 2003:18, italics in original).

"entrepreneurship requires the existence of opportunities, or situations in which people believe that they can use new means-ends frameworks to recombine resources to generate profit" (Shane 2003:6, italics added).
}

\footnotetext{
${ }^{6}$ Prospective use of the term might be defended on the grounds that an opportunity exists but has not been exploited (successfully) yet. Such claims can never be refuted. There is always tomorrow.
} 
From a critical realist standpoint, Shane operates with contradictory conceptions of opportunity because he conflates circumstances with agential beliefs about those circumstances. These are not two ways of saying the same thing; ontologically, structural and cultural circumstances and agential beliefs are very different entities. In his secondary view, Shane treats the individual's beliefs as necessary for the existence of an opportunity: if no individual believes a profit can be made, then there is no opportunity. Yet this contradicts Shane's primary argument that opportunities exist independently of the observer. The individual-opportunity nexus would be unintelligible if the ontological separation between individual and opportunity was not intended because if the existence of the opportunity is dependent on the individual's beliefs then the individual would be on both sides of the nexus. Shane's secondary view collapses opportunity as a feature of the external environment into the entrepreneur's beliefs about it. Conflating structure and agency prohibits them being prised apart to investigate their causal interplay (Archer 1995).

Using a single concept, opportunity, to refer to circumstances and agential beliefs plagues the discovery literature. In framing their theoretical and empirical work, researchers citing Shane as authority for the approach they take often switch between his primary and secondary definitions of opportunity, usually without acknowledgement. Conceptual slippage is evident in shifts between what are referred to as objective opportunities, on the one hand, and potential or perceived opportunities on the other (van Burg and Romme 
2014). By using terms such as search, discovery, identification and recognition, the independent existence of opportunities is assumed (Gartner et al. 2003). ${ }^{7}$

We illustrate the problem of switching definitions with a few examples; the literature offers many more. Casson and Wadeson (2007) conceive of opportunities as potentially profitable but hitherto unexploited projects. But if opportunities can only be identified retrospectively, how can we know in advance that a hitherto unexploited project will be profitable and therefore meet the definition of an opportunity? Baron (2006) defines an opportunity as a perceived means of generating economic value that previously has not been exploited and is not currently being exploited by others. But, if no-one perceives a means of generating value, then presumably an opportunity does not exist. Similarly, Ucbasaran et al. (2008) investigate whether respondents had identified, and pursued, an opportunity - but not whether they had exploited it. Again, because opportunities can only be identified once exploited, Ucbasaran et al. must be referring to respondents' beliefs that opportunities existed. A final example comes from Dahlqvist and Wiklund (2012). Defining opportunities as objective and discoverable, they operationalise them in terms of respondent assessments of the market newness of their perceived opportunity. Defining opportunities as circumstances independent of the entrepreneur and then switching to definitions based on beliefs about them, conflate the two, with contradictory consequences for theorising entrepreneurial action.

\footnotetext{
${ }^{7}$ This is not entirely the case. Baker et al. (2005), for example, use the language of discovery while referring to opportunities as inescapably subjective and enacted. Such complications add further urgency to re-examining the opportunity concept.
} 
Some have responded to this conceptual ambiguity by distinguishing first- and third-person opportunities (McMullen and Shepherd 2006) and 'opportunity for me' accounts (Haynie et al. 2009). These adjustments do not, however, overcome the problems of conceptualising opportunity coherently. McMullen and Shepherd (2006) define third-person opportunities in terms of a prospective entrepreneur's belief that triggers a decision-making process (McMullen and Shepherd 2006) and to first-person opportunities in terms of an entrepreneur deciding "that a possible third-person opportunity is an opportunity for him or her" (McMullen and Shepherd 2006:138). Use of the term 'possible' indicates that outcomes are uncertain, so this can only refer to the entrepreneur's belief that action will produce successful outcomes - not that the perceived opportunity will necessarily culminate in a profitable sale, which can only be known retrospectively. Haynie et al. (2009:339) focus on the process by which entrepreneurs evaluate a given opportunity, presupposing it exists prior to, and independent of, the entrepreneur's evaluation - in which case its status as a profitable prospect is uncertain at the time of evaluation. Both studies therefore blur belief and outcome.

Martin and Wilson (2014), and Ramoglou and Tsang (2015), using critical realist ideas, propose novel conceptions of opportunity as the circumstances that enable entrepreneurial change to happen (Martin and Wilson 2014) or as the propensity for market demand to be actualised into profits through the introduction of novel products and services (Ramoglou and Tsang 2015). ${ }^{8}$ Successful outcomes are therefore assumed. Entrepreneurs discover

\footnotetext{
${ }^{8}$ Martin and Wilson's (2014) approach might be termed the causal powers theory of opportunity development; Ramoglou and Tsang (2015) name theirs the actualisation approach. We discuss them here because, like discovery approaches, they define opportunity wholly or partly in terms of circumstances.
} 
what is possible by actualising it through their activities. These approaches tackle the implicit actualism in discovery approaches, that opportunities are concretely present even if unobserved (Ramoglou and Tsang 2015). This kind of thinking is certainly more in keeping with our own approach, based on a deep ontology of causal powers, actions and events, and experience.

In a subsequent paper, Wilson and Martin (2015) specify what they refer to as the boundary conditions of opportunity, structural and agential, that enable them to demarcate opportunity from the wider category of possibility, linking conditions of action to a particular goal-seeking entrepreneur; Ramoglou and Tsang (2015) also refer to the inevitable subjectivity of profit goals. ${ }^{9}$ Opportunity explicitly refers to circumstances, or potentials, that are activated by the entrepreneur. But, in addition to adding yet another layer of meaning to a heavily-laden concept of opportunity, we believe this approach does not avoid the problem of conflation of structure and agency that afflicts Shane and others operationalising his primary view in empirical work. In any actual, concrete situation, agential beliefs and goals, and social context, are necessary ingredients of a social scientific explanation of entrepreneurial action, but merging them in an abstract conception of opportunity obscures rather than illuminates. From a critical realist standpoint, conjoining circumstances and agential belief in an abstract definition of opportunity makes opportunities agent-dependent, that is, if the agent does not believe there is an opportunity, then one does not exist. Ultimately, this collapses the possibilities inherent in a

\footnotetext{
${ }^{9}$ The subjectivity of profit goals radically relativises the concept of opportunity. Conceivably, an entrepreneur might operate an unprofitable business, possibly because $s /$ he hopes to make a profit in future. Such loss-making might constitute a subjectively-acceptable level of performance, at least for a while: is this an opportunity?
} 
particular context into agential beliefs about, or perceptions of, that context. To avoid conflation, opportunity must be conceptualised as a property of the context - a potential for an action or event to happen independent of anyone's beliefs about, or intentions towards, it.

But, then, to describe the circumstances within which action occurs as an opportunity in the absence of an intentional agent seems odd - as the term seems to require an agent who might find circumstances favourable to his/her aims. Gartner (2014:25, italics added) captures this idea when he states that possibilities become opportunities when they are perceived as both desirable and feasible, a position that necessarily requires a human perceiver. If we follow Wilson and Martin (2015), then, we can either have conflation of structure and agency, if we include reference to the entrepreneur in an abstract concept of opportunity, or we can utilise an agent-centred concept incorporating reference to intentions to describe a set of circumstances that exist independent of any particular agent's beliefs and intentions!

Turning to Ramoglou and Tsang (2015), it is unclear what is to be gained by referring to the conditions that pre-date profit actualisation as an opportunity once they have been actualised. Telling us after Microsoft has grown into a business empire that Bill Gates had an opportunity beforehand adds nothing to explaining how specific activities in particular circumstances produced that empire. The term opportunity seems empty, lacking specificity regarding what aspects of circumstances made which actions, and effects, possible. Any successful entrepreneurial action (however defined) might, of course, be redescribed, retrospectively, as discovering an opportunity. We are not convinced there is anything to be 
gained by doing that, particularly in light of the contrasting uses of the concept. The less ambiguous term 'conditions of action' avoids this problem. It can be integrated into explanations of entrepreneurial action without assuming any particular outcome and can therefore be used in relation to current entrepreneurial actions prior to the production of their effects. Entrepreneurial projects that prove to be non-profitable are important too because, when acted upon, they influence market conditions which, in turn, affect all market agents. It also avoids the problem, acknowledged by the authors, of being unable to distinguish a non-opportunity from an unactualised (real, but unknown) opportunity.

Summarising, Shane conflates two radically different conceptions of opportunity - as situations ripe for profit-making and as subjective beliefs. The concept of opportunity cannot refer sensibly to both. More recent critical realist-inspired work constitutes an advance on Shane by deepening the ontological framework for explaining entrepreneurial action but also either falls prey to the same problem of conflation, or adopts the vocabulary of opportunity to refer to circumstances retrospectively when it is not clear what is to be gained from doing so. A non-opportunity-based analytical framework might offer a superior, less confusing, means of explaining entrepreneurial action.

\section{OPPORTUNITY CREATION}

Schumpeter (1934) is regarded as the precursor of the creation approach, emphasising the role of entrepreneurs as initiators of change and creators of new resource combinations. Advocates of creation conceive of opportunities as subjectively imagined and enacted by entrepreneurs, through interaction with stakeholders, including investors and customers, rather than caused by changes in what they term exogenous factors such as technology 
(Bhave 1994; Chiasson and Saunders 2005; Fletcher 2006; Sarason et al. 2006; Alvarez and Barney 2007; Dimov 2007; Endres and Woods 2007; Hjorth 2007; Wood and McKinley 2010; Popp and Holt 2013; Tocher et al. 2015). In this view, opportunities possess no prior, independent existence separate from entrepreneur/stakeholder interaction (Gartner et al. 2003; Dimov 2011). Opportunity creation is conceptualised as an unfolding, non-linear process during which venture ideas are intuited and refined, relationships with stakeholders formed and transformed, resources acquired and mobilised, and may refer to the process of 'groping' towards a sale or to the sale itself (Dimov 2011). For those defining opportunity in terms of sales, until the sale is achieved, the existence and precise nature of the opportunity is uncertain (Sarasvathy 2001; Ardichvili et al. 2003; Dimov 2011; Popp and Holt 2013).

Opportunity creation studies are intended to provide a more relational account of entrepreneurial processes (Korsgaard 2013). For some, opportunities are created in a process of conceptualisation, objectification and enactment whereby opportunities are conceived in thought, objectified through interactions with peers and then enacted or abandoned (Wood and McKinley 2010; Tocher et al. 2015). Others emphasise the role of language in the actualisation of opportunities in networks of interpersonal relations (Cornelissen and Clarke 2010; Spedale and Watson 2014). Yet others stress the emergent, collective process of opportunity creation arising from interaction between multiple agents with no single, originating entrepreneur (Maine et al. 2015; Overholm et al. 2015).

Perhaps the fundamental turning point in the career of the opportunity concept came when advocates of opportunity creation appropriated the term while, at the same time, transforming its meaning to refer to agents' activities or beliefs, rather than to the context 
of action as discovery thinkers ostensibly use it. Although the emphasis of creation on agency and the relational aspects of entrepreneurial action is warranted, like others, we are not convinced that appending the label opportunity to activities adequately conceptualised in other terms offers any new theoretical insight (Ramoglou and Zyglidopolous 2015). In creation accounts, the term opportunity simply redescribes activities such as having a business idea, acquiring, combining and mobilising resources, networking with stakeholders, creating new ventures and achieving a product sale - but contributes nothing to enhance understanding. There is no need to proliferate terms unnecessarily when well-established concepts already exist. Opportunity creation analysts might instead have reverted to existing terms to refer to their social objects of interest. This has been a major source of the confusion evident in discussions of opportunity.

To repeat our criticism of the discovery approach, business ideas, and practices such as resource acquisition, combination and mobilisation, setting up a new venture and making a sale are, ontologically speaking, distinct social objects and should be conceptualised as such. There is a difference between imagining a future, engaging in specific practices to achieve it and accomplishing it. Wood and McKinley (2010), for instance, go some way to acknowledging the distinction between ideas and enacted practices, yet retain the term opportunity to refer to both a business idea and the sale.

These problems mirror wider difficulties with constructionist approaches that often obscure whether researchers' concepts refer to entrepreneurs' cognitive, linguistic or discursive articulations (what entrepreneurs think or say) or to their enacted, embodied practices (what entrepreneurs do) (Sayer 2000). The deep ontology of powers, and actions and events 
seeks to avoid collapsing practices into experience. The entrepreneur's belief that an opportunity exists is ontologically distinct from the practice of groping towards, or achieving, a product sale, even though the belief causally influences such practices and their consequences.

Opportunity creation researchers often assume a range of non-experiential social objects in their analyses such as competitive market or industry imperfections (Alvarez and Barney 2007) or social structures (Wood and McKinley 2010; Tocher et al. 2015). Such social objects are typically presented as either conditions or consequences of action. Alvarez et al. (2013) refer to objective reality - which is odd for a constructionist approach. One can only presume these authors wish to treat objective reality as exerting real causal effects on entrepreneurs. Such forms of constructionism, however, are potentially consistent with a stratified critical realist social ontology that conceptualises social reality as comprising more than that which entrepreneurs and their stakeholders describe it to be. Proponents of opportunity creation have overstated the differences between constructionism and critical realism in order to argue that the latter necessarily underpins discovery accounts (Alvarez and Barney 2010) -moderate forms of constructionism, accepting the crucial causal role of agents and culture in the production of social objects, are necessary for critical realist explanation. For critical realists it is easy to accommodate perceptions and beliefs and other social objects (perhaps competitive market imperfections and social structures) within a unified ontological framework. There are always structural and cultural conditions of possibility for any social activity or belief; these conditions are irreducible to perceptions (or conceptual, linguistic or discursive constructions) of them (Bhaskar 1979; Sayer 1992). 


\section{THE IMPOSSIBILITY OF SYNTHESIS}

Attempts to synthesise different conceptions of opportunity, or to treat discovery and creation as different types of opportunity, reveal a failure to engage in ontological theorising. Given the very different ontological commitments underpinning the main discovery and creation definitions of opportunity, synthesising the two in an abstract concept specifying the necessary properties and powers of opportunity is impossible. An abstract concept of opportunity cannot sensibly refer to an agential belief or imagined future and to an action or event and to circumstances. Beliefs, actions and circumstances are distinct kinds of object and need to be distinguished conceptually in order that their causal connections can be identified in studies of actual, concrete cases. Indeed, some use the term opportunity belief to distinguish subjective states from activities and the social context (Shepherd et al. 2007; Wood et al. 2014). Reviews that encompass discovery- and creation-based studies compound the confusion when they suggest the possibility of synthesis without acknowledging the ontological difficulties (e.g. Short et al. 2010; Mainela et al. 2014).

Some distinguish discovery and creation as distinct types of opportunity (Zahra 2008; Alvarez and Barney 2010; Baron and Henry 2010; Overholm 2015; Valliere 2015). Treating beliefs, actions and circumstances as variants of a single entity - opportunity - reflects a chaotic conception (Sayer 1992). For instance, de Jong and Marsili (2015) attempt to combine what they term 'Kirznerian' and 'Schumpeterian' opportunities, intended to reflect discovery and creation thinking respectively, into a single continuum of opportunity types. This attempt at synthesis treats opportunities as though the difference between discovery and creation is one of degree and overlooks entirely their very different ontological 
assumptions. Attempts to distinguish discovery and creation as distinct types of opportunity are, we suggest, doomed because a coherent concept cannot refer both to an object that exists prior to entrepreneurial action (discovery), and to one that only comes into being through, or as a consequence of, action (creation).

\section{TOWARDS A NEW FRAMEWORK FOR THE STUDY OF ENTREPRENEURIAL ACTION}

Readers may wonder what researchers would study if the concept of opportunity was abandoned. This would be an unfortunate legacy, demonstrating the power of a conceptual image to bewitch an audience. We share Gartner (2003) and Davidsson's (2015) diagnosis of the problems with the opportunity concept but go beyond them to provide both an ontologically-based critique of conceptions of opportunity and to offer an ontologicallygrounded framework to support explanation of the causes, processes and outcomes of entrepreneurial action, without a concept of opportunity. Our approach shares much in common with other critical realist-inspired work with its emphasis on the possibilities for action afforded by the causal powers, or propensities, inherent in a particular social context (Martin and Wilson 2014; Wilson and Martin 2015; Ramoglou and Tsang 2015). We do not, however, try to resurrect an opportunity approach that might elicit the unwanted reabsorption of particular assumptions into analysis and explanation.

We propose a new framework centring on entrepreneurial action and the structural and cultural conditions that enable, motivate and constrain it. We use the less ambiguous concepts of 'entrepreneurial project' to refer to investments in resources intended to create goods and services for market exchange, 'conditions of action' to refer to the context within which such projects are acted upon, and a bundle of well-known terms such as imagining 
and developing a business idea, resource acquisition, combination and mobilisation, networking, new venture creation and making a sale to refer to particular actions. Our formulation of conditions of action avoids the conceptual confusion that comes with multiple meanings of opportunity (as belief, action or circumstances) and imposes no assumption that entrepreneurs know how conditions enable their activities or that successful consequences follow from entrepreneurial actions.

Entrepreneurs consciously formulate projects to achieve their goals and deliberate over what actions to take to attain them. Projects may combine 'business' and 'personal' goals, though agents may not make such distinctions themselves. Conceptualised in this way, projects are long- and medium-term goals to which agents commit themselves, rather than simply decisions to engage in specific practices (Archer 2000). The content of projects is likely to be highly variable between entrepreneurs and over time. Use of the term project implies no particular type of aim or organisational context. It might be difficult to pinpoint precisely when a project starts and ends because of the blurred boundary between thought and action. We argue that a project exists when an agent consciously adopts a goal following reflexive deliberation over ends and dedicates themselves to achieving it. Investments of skill, effort and material resources manifest the project in embodied practices, for instance, buying raw materials and other inputs, hiring or redeploying labour, securing finance or setting up a limited company. Entrepreneurs may, of course, revise or abandon projects as a consequence of action.

Entrepreneurs pursue projects largely under conditions not of their own making, uncertain whether their actions will succeed. They act in, and on, a natural world of non-human 
resources, a practical world of human-made artefacts and a socio-cultural world of relations with other people, to create new goods and services for market exchange in the belief that this will enable them to realise some goal. This allows for diversity in goals (levels of economic return deemed subjectively acceptable), business practices and interactions with stakeholders, and outcomes. It is these activities, the structural and cultural conditions that make them possible, and their consequences, that researchers should theorise anew. For this, they need no concept of opportunity.

Adopting a morphogenetic framework of socio-historical change facilitates more powerful theorising (Archer 1995; Mole and Mole 2010), connecting structural, cultural and agential causal powers in an interactive, emergent process. Structure, culture and agency are necessary conditions of all entrepreneurial action and therefore all are necessary ingredients in an adequate explanation of its causes, processes and consequences. Such a framework helps to rebalance explanations that treat entrepreneurial action in individualist and voluntarist terms as if untethered to any social context. Entrepreneurs never construct something out of nothing (contrast Baker and Nelson 2005 and Chiles et al. 2007); there are always enabling conditions.

History bequeaths to contemporary agents the structural and cultural settings in which they must necessarily act, although agents must reflect on their circumstances in order to formulate, and seek to realise, particular projects (Archer 2000, 2003). The necessity for agents to interpret their circumstances in order to pursue projects does not deny the preexistence, autonomy and causal efficacy of social structures (Bhaskar 1979) and cultures (Archer 1988; Porpora 2015). Circumstances are not simply conceptual, linguistic or 
discursive constructions but, rather, as Martin and Wilson (2014) and Ramoglou and Tsang (2015) suggest, real objective conditions with particular causal powers that entrepreneurs might activate, intentionally or unwittingly, through their activities. ${ }^{10}$ Both the dominant discovery and, particularly, the creation approaches lack an explicit deep social ontology, intended to capture the multiple causal powers generating actions/event. They thereby encourage individualist and voluntarist explanations that accord entrepreneurs excessive powers of agency.

Conceptualising context in terms of structure and culture directs attention to the relationships, resource distributions, institutions and cultural norms that pre-date and causally affect the actions of contemporary entrepreneurs. Possibilities for entrepreneurial action vary with many of the contextual features identified in prior research - including technology, and political/regulatory and social/demographic contexts (Shane 2003) - that vary over time. But possibilities also vary for particular entrepreneurs due to their particular positioning in relation to multiple structural and cultural contexts, as this has developed over their personal, family and business life courses (Jayawarna et al. 2013). Entrepreneurs are always already positioned in relation to particular structures and cultures that enable unequal command of, and motivation to use, financial resources, knowledge and skills, and social connections in particular ways (Thornton et al. 1999; Rouse and Jayawarna 2011; Eddleston and Powell 2012; Perry-Rivers 2016). Positions relate to how structures such as gender, class, and ethnicity have affected, and continue to shape, the life courses of entrepreneurs. Contrast the constrained resources and capacity to trade in lucrative

\footnotetext{
${ }^{10}$ Roscoe et al.'s (2013) study of an agricultural enterprise in Honduras makes the important observation that successful entrepreneurial action is often dependent upon favourable natural contexts too.
} 
markets of migrant female entrepreneurs using scarce time to provide low value-added services to deprived localities (Rouse and Mirza, 2014) with affluent male entrepreneurs providing higher value services.

Circumstances privilege some entrepreneurs while, at the same time, frustrating the efforts of others to further their projects (Rouse and Kitching, 2006), primarily due to the actions of structurally- and culturally-positioned others pursuing their own goals (Archer 1995). In some circumstances, entrepreneurs might be better described as lucky (Görling and Rehn 2008) than exercising good judgment (Foss and Klein 2012). The good fortune particular circumstances bestow on particular entrepreneurs further encourages analysis of structural influences such as class (Jayawarna et al. 2014), gender (Hughes et al. 2012; Rouse et al. 2013) or ethnicity (Carter et al. 2015) and discourages disproportionate attention to information-search and -processing capabilities (Baron 2006; Sleptsov and Anand 2008).

To argue that actions are possible means only that a particular agent could act in a particular way given prevailing structural and cultural conditions, although this might only be discoverable later. Because only one future is ever actualised, we can never be certain what other possibilities were inherent in a given set of historical circumstances. Favourable conditions, however, never suffice to ensure an event occurs, given the agent's powers to act otherwise (Ramoglou 2013). Agents must choose how to deploy their limited resources at particular moments in history; they cannot pursue all projects open to them simultaneously. 
The structured, emergent, processual and open-ended character of social life means that possibilities for action are heavily time-, space- and position-dependent. Circumstances undergo a continuous process of gentle or rapid change, partly as a consequence of what entrepreneurs do but mainly as a consequence of the actions of the multitude of others, shaping possibilities for action for particular agents in particular times and places. Entrepreneurs cannot wish the context away; they must deal with the world as it confronts them in all of its dynamic complexity.

The framework we propose formalises and systematises what we believe many entrepreneurship and small business researchers already do to some degree; Fleetwood and Ackroyd (2004) make a similar argument in relation to management and organisation studies. Where researchers refer to unobservable social structures such as class, gender, ethnicity, organisations or markets, or to cultural objects such as social norms, or discourses, to explain some aspect of entrepreneurial action, they adopt, implicitly, a layered social ontology that distinguishes the causal powers of structures and cultures, from actual practices and experiences. Adopting a critical realist position explicitly can support a more systematic approach to thinking through the implications of a stratified social ontology for research practice and analysis (Edwards et al. 2014).

The vocabulary of entrepreneurial projects and conditions of action provides a more useful set of concepts for explaining the causes, processes and consequences of entrepreneurial action than opportunity. The concept of conditions of action is similar to Davidsson's (2015) 'external enablers' but the latter are not conceptualised in terms of a deep ontology of powers, actions/events, and experience. This risks slipping back into the actualism 
debilitating discovery views that treats opportunities as circumstances that are present but unobserved rather than as circumstances that need to be acted in, and on, by entrepreneurs in order to actualise, and discover, the causal powers that exist within a particular situation.

We propose that the contradictory concept of opportunity be dispensed with because it hinders theoretical development regarding how new goods and services come into being through interactions between entrepreneurs and their structural and cultural contexts. Studies unnecessarily and unhelpfully framed around the opportunity concept impede explanation. Given the time and effort researchers have invested in the concept, however, it is unlikely the term will be discarded lightly, even if persuaded of our arguments. Anticipating some reluctance, we request that researchers at least take the important precaution of distinguishing entrepreneurial project, business or venture idea, or opportunity belief, from actual practices, such as creating new organisations, and from the wider contexts within which they act.

\section{CONCLUSION}

We have reviewed and critiqued the dominant discovery and creation conceptions of entrepreneurial opportunity from the standpoint of critical realist social ontology. This has enabled us to identify contradictions and inconsistencies in definition and differences in ontological presuppositions that seriously hinder progress in theorising the causes, processes and consequences of entrepreneurial action, defined in terms of investments in resources intended to create new goods and services for market exchange. Critical realism, with its explicit attention to ontology and its emphasis on clear conceptualisation, provides powerful resources for such an analysis. Discovery and creation are presented as opposing 
approaches but proponents of both commit a similar error in switching between conceptions of opportunities as radically different kinds of social object - as social situations possessing profit-making prospects, as particular practices, and as agential beliefs or imagined futures. Using the same term to refer to all three types of object has produced conceptual chaos and theoretical stagnation.

Striking a more positive note for future research, critical realism provides valuable conceptual resources for explaining how entrepreneurial action emerges from the continuous interaction between human agents and their conditions of action. Future conceptual work and empirical research might explore the definition and interdependencies of entrepreneurial projects and examine how contexts shape their formulation and execution. As entrepreneurs are variably-positioned to exploit circumstances, it would be surprising if conditions did not profoundly shape their projects.

Rather than simply looking at entrepreneurs' cognitive characteristics and informationprocessing capabilities, critical realism directs us to investigate the structural and cultural contexts of action and how these enable, motivate and constrain entrepreneurial projects and the creation of new goods and services. While calls for greater attention to context are frequently made, few adopt an explicit critical realist stance seeking to explain how structural and cultural positioning influences entrepreneurial action, although elements of this kind of explanation are present in a number of studies. Authoritative explanation depends on adoption of a deep social ontology of causal powers, actions and events, and experience. 
Entrepreneurs must act to realise their projects, but they cannot bend the social world, voluntaristically, to their wishes. Entrepreneurs act in, and on, a socially-structured and culturally-shaped world which may resist their efforts to transform it into new products, firms and markets. Entrepreneurs' projects and performance are necessarily shaped by the actions of structurally- and culturally-positioned others, close and distant, including many of whom the entrepreneur is, and will forever remain, unaware. Discarding the opportunity concept should not lead to abandonment of attention to the influence of the environment but rather to renewed concern with explaining how context, conceptualised in structural and cultural terms, enables, motivates and constrains particular entrepreneurs to engage in particular forms of entrepreneurial action in particular times and places.

\section{REFERENCES}

Akram S (2013) Fully unconscious and prone to habit: the characteristics of agency in the structure and agency dialectic. Journal for the Theory of Social Behaviour 43(1):45-65.

Alvarez S and Barney J (2007) Discovery and creation: alternative theories of entrepreneurial action. Strategic Entrepreneurship Journal 1(1-2):11-26.

Alvarez S and Barney J (2010) Entrepreneurship and epistemology: the philosophical underpinnings of the study of entrepreneurial opportunities. Academy of Management Annals 4(1):557-583.

Alvarez S, Barney J and Anderson P (2013) Forming and exploiting opportunities: the implications of discovery and creation processes for entrepreneurial and organizational research. Organization Science 24(1):301-317.

Archer M (1988) Culture and Agency. Cambridge:Cambridge University Press.

Archer M (1995) Realist Social Theory: The Morphogenetic Approach. Cambridge:Cambridge University Press.

Archer M (2000) Being Human: The Problem of Agency. Cambridge:Cambridge University Press.

Archer M (2003) Structure, Agency and the Internal Conversation. Cambridge:Cambridge University Press. 
Archer M (2014) Introduction: stability or stabilisation - on which would morphogenic society depend? In: Archer M (eds) Late Modernity: Trajectories Towards Morphogenic Society. London:Springer, pp.1-20.

Ardichvili A, Cardozo R and Ray S (2003) A theory of entrepreneurial opportunity identification and development. Journal of Business Venturing 18(1):105-123.

Arend RJ (2014) Promises, premises...an alternative view on the effects of the Shane and Venkataraman AMR note. Journal of Management Inquiry 23(1):38-50.

Baker T, Gedajlovic E and Lubatkin M (2005) A framework for comparing entrepreneurship processes across nations. Journal of International Business Studies 36(5):492-504.

Baker T and Nelson RE (2005) Creating something from nothing: resource construction through entrepreneurial bricolage. Administrative Science Quarterly 50(3):329-366.

Baron R (2006) Opportunity recognition as pattern recognition: how entrepreneurs 'connect the dots' to identify new business opportunities. Academy of Management Perspectives 20(1):104-119.

Baron R and Henry RA (2010) How entrepreneurs acquire the capacity to excel: insights from research on expert performance. Strategic Entrepreneurship Journal 4(1):49-65.

Bhaskar R (1978) A Realist Theory of Science ( $2^{\text {nd }}$ ed). Hassocks:Harvester.

Bhaskar R (1979) The Possibility of Naturalism. Brighton:Harvester Wheatsheaf.

Bhaskar R (1986) Scientific Realism and Human Emancipation. London:Verso.

Bhave MP (1994) A process model of entrepreneurial venture creation. Journal of Business Venturing 9(3):223-242.

Busenitz L, Plummer L, Klotz A, et al. (2014) Entrepreneurship research (1985-2009) and the emergence of opportunities. Entrepreneurship Theory and Practice 38(5):981-1000.

Bygrave W and Hofer C (1991) Theorizing about entrepreneurship. Entrepreneurship Theory and Practice 16(2):13-21.

Carter, S., Mwaura, S., Ram, M., Trehan, K., Jones, T., 2015. Barriers to ethnic minority and women's enterprise: existing evidence, policy tensions and unsettled questions. International Small Business Journal 33(1):49-69.

Casson M and Wadeson N (2007) The search for entrepreneurial opportunities. History of Economic Ideas 15(1):137-158.

Chiasson M and Saunders C (2005) Reconciling diverse approaches to opportunity research using the structuration theory. Journal of Business Venturing 20(6):747-767. 
Chiles T, Bluedorn AC and Gupta VK (2007) Beyond creative destruction and entrepreneurial discovery: a radical Austrian approach to entrepreneurship. Organization Studies 28(4):467493.

Chiles T, Vultee D, Gupta V, et al. (2010) The philosophical foundations of a radical Austrian approach to entrepreneurship. Journal of Management Inquiry 19(2):138-164.

Collier A (1994) Critical Realism. London:Verso.

Cornelissen JP and Clarke JS (2010) Imagining and rationalizing opportunities: inductive reasoning and the creation and justification of new ventures. Academy of Management Review 35(4):539-557.

Crawford GC, Dimov D and McKelvey B (2016) Realism, empiricism, and fetishism in the study of entrepreneurship. Journal of Management Inquiry 25(2):168-170.

Dahlqvist J and Wiklund J (2012) Measuring the market newness of new ventures. Journal of Business Venturing 27(2):185-196.

Davidsson P (2015) Entrepreneurial opportunities and the entrepreneurship nexus: a reconceptualization. Journal of Business Venturing, 30(5):674-695.

de Jong JPJ and Marsili O (2015) The distribution of Schumpeterian and Kirznerian opportunities. Small Business Economics 44(1):19-35.

Dimov D (2007) Beyond the single-person, single-insight attribution in understanding entrepreneurial opportunities. Entrepreneurship Theory and Practice 31(5):713-731.

Dimov D (2011) Grappling with the unbearable lightness of opportunities. Entrepreneurship Theory and Practice 35(1):57-81.

Eckhardt J and Shane S (2003) Opportunities and entrepreneurship. Journal of Management 29(3):333-349.

Eckhardt J and Shane S (2010) An update to the individual-opportunity nexus. In: Acs Z and Audretsch D (eds) Handbook of Entrepreneurship Research $\left(2^{\text {nd }}\right.$ ed). Springer:New York. Pp.47-76.

Edwards PK, O'Mahoney J. and Vincent S (2014) Studying Organizations Using Critical Realism: A Practical Guide. Oxford: Oxford University Press.

Elder-Vass D (2010) The Causal Power of Social Structures. Cambridge:Cambridge University Press.

Elder-Vass D (2012) The Reality of Social Construction. Cambridge:Cambridge University Press. 
Endres AM and Woods CR (2007) The case for more 'subjectivist' research on how entrepreneurs create opportunities. International Journal of Entrepreneurial Behavior and Research 13(4):222-234.

Fleetwood S (2005) The ontology of organisation and management studies: a critical realist approach. Organization 12(2):197-222.

Fleetwood S (2008) Structure, institution agency, habit, and reflexive deliberation. Journal of Institutional Economics 4(2):183-203.

Fleetwood S, Ackroyd S. Eds. 2004. Critical Realist Applications in Organisation and Management Studies. London:Routledge.

Fletcher D (2006) Entrepreneurial processes and the social construction of opportunity. Entrepreneurship and Regional Development 18(5):421-440.

Foss NJ, Klein PG (2012) Organizing Entrepreneurial Judgment: A New Approach to the Firm. Cambridge:Cambridge University Press.

Gartner W, Carter N and Hills G (2003) The language of opportunity. In: Steyaert C and Hjorth D (eds) New Movements of Entrepreneurship. Cheltenham:Edward Elgar.

Gartner W (2014) Notes towards a theory of entrepreneurial possibility. In: Chell E and Karataş-Özkan M (eds) Handbook of Research on Small Business and Entrepreneurship. Cheltenham:Edward Elgar, pp.25-37.

Görling S and Rehn A (2008) Accidental venture - a materialist reading of opportunity and entrepreneurial potential. Scandinavian Journal of Management 24(2):94-102.

Groff R. 2004. Critical Realism, Post-positivism and the Possibility of Knowledge. London:Routledge.

Groff R. 2008. Introduction: realism about causality. In: Groff R (ed) Revitalizing Causality: Realism about Causality in Philosophy and Social Science. London:Routledge, pp.1-10.

Hansen D, Schrader R and Monllor J (2011) Defragmenting definitions of entrepreneurial opportunity. Journal of Small Business Management 49(2):283-304.

Haynie JM, Shepherd DA and McMullen JS (2009) An opportunity for me? The role of resources in opportunity evaluation decisions. Journal of Management Studies 46(3):337361.

Hjorth D (2007) Lessons from lago: narrating the event of entrepreneurship. Journal of Business Venturing 22(5):712-732.

Hughes KD, Jennings JE, Brush C, Carter S and Welter F (2012) Extending women's 
entrepreneurship research in new directions. Entrepreneurship Theory and Practice 36(3):429-442.

Jayawarna D, Rouse J and Kitching J (2013) Entrepreneur motivations and life course. International Small Business Journal 31(1):34-56.

Jayawarna D, Rouse J and Macpherson A (2014) Life course pathways to business start-up. Entrepreneurship and Regional Development 26(3-4):282-312.

Kirzner I (1973) Competition and Entrepreneurship. Chicago:University of Chicago Press.

Kirzner I (2009) The alert and creative entrepreneur: a clarification. Small Business Economics 32(2):145-152.

Klein P (2008) Opportunity discovery, entrepreneurial action, and economic organization. Strategic Entrepreneurship Journal 2(3):175-190.

Korsgaard S (2013) It's really out there: a review of the critique of the discovery view of opportunities. International Journal of Entrepreneurial Behaviour and Research 19(2):130148.

Lawson T (1995) A realist perspective on contemporary "economic theory". Journal of Economic Issues 29(1):1-32.

Lawson T (1997) Economics and Reality. London:Routledge.

Layder D (2006) Understanding Social Theory (2nd ed). London:Sage.

Luke D, and Bates S (2015) Using critical realism to explain indeterminacy in role behaviour systematically. Journal for the Theory of Social Behaviour 45(3):331-351.

Maine E, Soh P-H and Dos Santos N (2015) The role of entrepreneurial decision-making in opportunity creation and recognition. Technovation 39-40(May-June):53-72.

Mainela T, Puhakka V and Servais P (2014) The concept of international opportunity in international entrepreneurship: a review and a research agenda. International Journal of Management Reviews 16(1):105-129.

Martin L and Wilson N (2014) Opportunity, discovery and creativity: a critical realist perspective. International Small Business Journal, published online, 10 October. DOI 10.1177/0266242614551185

Martinez Dy A, Martin L and Marlow S (2014) Developing a critical realist positional approach to intersectionality. Journal of Critical Realism 13(5):447-466.

McMullen J and Shepherd D (2006) Entrepreneurial action and the role of uncertainty in the theory of the entrepreneur. Academy of Management Review 31(1):132-152. 
Mole KF and Mole M (2010) Entrepreneurship as the structuration of individual and opportunity: a response using a critical realist perspective: comment on Sarason, Dean and Dillard. Journal of Business Venturing 25(2):230-237.

Overholm H (2015) Collectively created opportunities in emerging ecosystems: the case of solar service ventures. Technovation 39-40 (May-June) 14-25.

Perry-Rivers P (2016) Stratification, economic adversity, and entrepreneurial launch: the effect of resource position on entrepreneurial strategy. Entrepreneurship Theory and Practice, 40(3):685-712.

Popp A and Holt R (2013) The presence of entrepreneurial opportunity. Business History 55(1):9-28.

Porpora D (2015) Reconstructing Sociology: The Critical Realist Approach.

Cambridge:Cambridge University Press.

Ramoglou S (2013) Who is a 'non-entrepreneur'? Taking the 'others' of entrepreneurship seriously. International Small Business Journal 31(4):432-453.

Ramoglou S, Tsang E (2015) A realist perspective of entrepreneurship: opportunities as propensities. Academy of Management Review published online October 14, doi: 10.5465/amr.2014.0281

Ramoglou S and Zyglidopolous SC (2015) The constructivist view of entrepreneurial opportunities: a critical analysis. Small Business Economics 44(1):71-78.

Roscoe P, Discua Cruz A and Howorth C (2013) How does an old firm learn new tricks? A material account of entrepreneurial opportunity. Business History 55(1):53-72.

Rouse J and Jayawarna D (2011) Structures of exclusion from enterprise finance. Environment and Planning C: Government and Policy 29(4):659-676.

Rouse J and Kitching J (2006) Do enterprise support programmes leave women holding the baby? Environment and Planning C: Government and Policy 24(1):5-19.

Rouse J and Mirza A. (2014) Empowering British Bangladeshi Women Through Small Enterprise? Oxford:Oxfam.

Rouse, J., Treanor, L. and Fleck, E. (2013) The gendering of entrepreneurship: theoretical and empirical insights. International Journal of Entrepreneurial Behavior and Research 19(5):452-459.

Sarason Y, Dean T and Dillard JF (2006) Entrepreneurship as the nexus of individual and opportunity: a structuration view. Journal of Business Venturing 21(3):286-305. 
Sarasvathy S (2001) Causation and effectuation: toward a theoretical shift from economic inevitability to entrepreneurial contingency. Academy of Management Review 26(2):243263.

Sayer A (1992) Method in Social Science ( $2^{\text {nd }}$ ed). London:Routledge.

Sayer A (2000) Realism and Social Science. London:Sage.

Sayer A (2009) Reflexivity and the habitus. In: Archer M (ed) Conversations About Reflexivity. London:Routledge, pp.108-122.

Schumpeter J (1934) The Theory of Economic Development. Cambridge, Mass:Harvard University Press.

Searle J (2010) Making the Social World. Oxford:Oxford University Press.

Shane S (2000) Prior knowledge and the discovery of opportunities. Organization Science 11(4):448-469.

Shane S (2003) A General Theory of Entrepreneurship: The Individual-Opportunity Nexus. Cheltenham:Edward Elgar.

Shane S (2012) Reflections on the 2010 AMR decade award: delivering on the promise of entrepreneurship as a field of research. Academy of Management Review 37(1):10-20.

Shane S and Venkataraman S (2000) The promise of entrepreneurship as a field of research. Academy of Management Review 25(1):217-226.

Shepherd DA, McMullen JS and Jennings PD (2007) The formation of opportunity beliefs: overcoming ignorance and reducing doubt. Strategic Entrepreneurship Journal 1(1-2):7595.

Short JC, Ketchen D, Shook CL, et al. (2010) The concept of 'opportunity' in entrepreneurship research: past accomplishments and future challenges. Strategic Entrepreneurship Journal 36(1):40-65.

Sleptsov A and Anand J (2008) Exercising entrepreneurial opportunities: the role of information-gathering and Information-processing capabilities of the firm. Strategic Entrepreneurship Journal 2(4):357-372.

Spedale S and Watson T (2014) The emergence of entrepreneurial action: at the crossroads between institutional logics and individual life-orientation. International Small Business Journal 32(7):759-776.

Thornton P, Ribeiro-Soriano D and Urbano D (1999) The sociology of entrepreneurship. Annual Review of Sociology 25(1):19-46. 
Tocher N, Oswald SL and Hall DJ (2015) Proposing social resources as the fundamental catalyst toward opportunity creation. Strategic Entrepreneurship Journal 9(2):119-135.

Ucbasaran D, Westhead P and Wright M (2008) Opportunity identification and pursuit: does an entrepreneur's human capital matter? Small Business Economics 30(2):153-173.

Valliere D (2015) Entrepreneurial sensegiving and the attention contract. International Entrepreneurship Management Journal 11(1):77-94.

van Burg E and Romme AGL (2014) Creating the future together: toward a framework for research synthesis in entrepreneurship. Entrepreneurship Theory and Practice 38(2):369397.

Venkataraman S (1997) The distinctive domain of entrepreneurship research. In: Katz J and Brockhaus R (eds) Advances in Entrepreneurship, Firm Emergence and Growth, Volume 3. Greenwich, CT:JAI Press, pp.119-138.

Wilson N, Martin L (2015) Entrepreneurial opportunities for all? Entrepreneurial capability and the Capabilities Approach. International Journal of Entrepreneurship and Innovation 16(3):159-169.

Wood MS and McKinley W (2010) The production of entrepreneurial opportunity: a constructivist perspective. Strategic Entrepreneurship Journal 4(1):66-84.

Wood M, McKelvie A and Haynie JM (2014) Making it personal: opportunity individuation and the shaping of opportunity beliefs. Journal of Business Venturing 29(2):252-272.

Zahra S (2008) The virtuous cycle of discovery and creation of entrepreneurial opportunities. Strategic Entrepreneurship Journal 2(3):243-257.

Zahra S and Wright M (2011) Entrepreneurship's next act. Academy of Management Perspectives 25(4):67-83.

Zahra S, Wright M and Abdelgawad S (2014) Contextualization and the advancement of entrepreneurship research. International Small Business Journal 32(5):479-500. 